\title{
10 Phenotypic Plasticity and Evolutionary Transitions in Individuality
}

\author{
Dinah R. Davison and Richard E. Michod \\ University of Arizona
}

\section{CONTENTS}

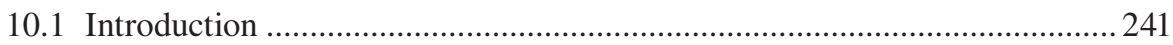

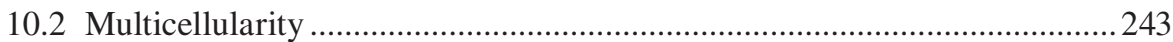

10.3 Plasticity and Group Formation in the Volvocine Green Algae..................245

10.4 Plasticity and Division of Labor in the Volvocine Green Algae ..................248

10.5 Other Evolutionary Transitions in Individuality ........................................2. 253

10.5.1 Group Formation in Choanoflagellates and Animals .....................253

10.5.2 Plasticity in Eusocial Insect Societies .......................................... 255

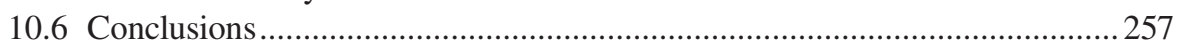

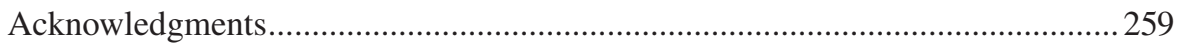

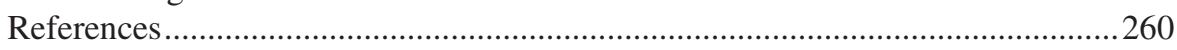

\subsection{INTRODUCTION}

Evolutionary transitions in individuality occur when the unit of selection and adaptation, the evolutionary individual, changes from one level of organization to another (Buss 1987; Maynard Smith and Szathmáry 1995; Michod 1999; Hanschen et al. 2017a). Examples involve some of the key events in the history of life, including the evolution of the cellular genome from groups of cooperative genes, the evolution of eukaryotic cells from bacterial and archaeal cells, the evolution of multicellular organisms from unicellular ancestors, and the evolution of eusocial societies from solitary ancestors. These transitions in individuality are rare evolutionary events, having occurred dozens of times, as compared to the millions of speciation events that have occurred throughout the history of life. Although rare, these evolutionary transitions have bestowed on life one of its most familiar characteristics, its hierarchical organization, in which biological individuals-genomes, cells, multicellular organisms, eusocial societies_-are comprised of groups of cooperating individuals from lower levels.

In this chapter we ask how phenotypic plasticity affected evolutionary transitions in individuality (see Table 10.1 for a summary of evolutionary transitions in individuality and the possible importance of phenotypic plasticity in each transition). 


\section{TABLE 10.1}

\section{The Potential Role of Phenotypic Plasticity in Four Key Evolutionary Transitions in Individuality}

\section{Evolutionary Transition in Individuality}

Origin of the genome in cells. The genome is a cooperative group of genes that can be selected for if it resides in a compartment, or cell-like structure (Michod 1983, 1999; Szathmary and Demeter 1987; Maynard Smith and Szathmáry 1995).

Origin of eukaryotes through endosymbiosis.

Origin of multicellularity

Origin of eusociality

\section{Potential Role of Plasticity}

Authors have hypothesized mobile genetic elements were important in the origin of genomes (Brosius 1999; Durand and Michod 2010; Ågren 2014; Koonin 2016). Genomic rearrangements, including the movement of transposable elements, can be induced by environmental stress and contribute to genomic plasticity (Wessler 1996; Bennett 2004; Leitch and Leitch 2008).

Some endosymbioses can be facultative and induced by environmental stress (Lamelas et al. 2011; Bellantuono et al. 2019). It is unclear whether the endosymbiotic origin of mitochondria and plastids in early eukaryotes was similar.

In this chapter, we develop the hypothesis that plasticity played a role in key steps such as the origin of group formation and the origin of cellular differentiation.

Plasticity is important in caste development and may have played a role in the origin of groups with a simple division of labor.

Plasticity research has predominantly focused on unicellular and multicellular organisms (Schlichting and Smith 2002), and researchers have hypothesized that phenotypic plasticity affected the origin of novel traits in both multicellular and unicellular organisms (West-Eberhard 2003; Levis and Pfennig 2016, 2021). What role did phenotypic plasticity play in the evolution of novel traits required for the transition from unicellular to multicellular organisms?

We break this question down by considering the role of phenotypic plasticity in the different stages of an evolutionary transition in individuality. For our purposes, the stages discussed in more detailed presentations of this theory (Michod 1999; Hanschen et al. 2015) may be condensed into two stages: (1) the formation of groups, and (2) the evolution of cooperation and conflict (including the evolution of division of labor or specialization in the fitness components of the group). Cooperation benefits the group but can be costly to individuals within the group. Group members may benefit from cheating and consuming common resources without contributing to the group, leading to the evolution of mechanisms that inhibit cheating and promote cooperation (Michod 1999; Michod and Roze 2001). Division of labor in the basic components of fitness, survival and reproduction, increases cooperation, decreases cheating, and, as a result, increases the degree 
of integration of the group so that group fitness is no longer the average of the fitnesses of group members. We focus on the evolutionary transition from unicellular individuals to multicellular individuals in the volvocine green algae, but briefly discuss the evolution of multicellularity in animals and the evolution of eusocial insect societies.

\subsection{MULTICELLULARITY}

The evolution of multicellular organisms from unicellular organisms is one of the most common evolutionary transitions in individuality and has occurred dozens of times. Multicellularity is distributed throughout eukaryotes and also occurs in bacteria and archaea (Bonner 1998; Fisher et al. 2013). Multicellularity may be obligate or facultative (Grosberg and Strathmann 2007; Resendes De Sousa António and Schulze-Makuch 2012; Fisher et al. 2013). Obligate multicellularity occurs when a protracted multicellular stage is always part of the life cycle, whereas facultative multicellularity occurs when the life cycle can be completed in the unicellular state, and multicellular structures only develop under certain environmental conditions. Both obligate and facultative multicellularity have evolved independently in multiple clades, including the lineage leading to vascular plants, green algae (including the volvocine green algae), bacteria, archaea, animals, brown algae, red algae, and fungi (Bonner 1998; Grosberg and Strathmann 2007; Fisher et al. 2013; Herron et al. 2013).

Facultative multicellularity occurs in response to environmental conditions in a variety of species (Resendes De Sousa António and Schulze-Makuch 2012; Fisher et al. 2013). In taxa such as the social amoeba, Dictyostelium, the facultatively multicellular stage is an integrated part of their life history and has been shaped by selection (Bonner 2003). In cases of facultative multicellularity in which the multicellular forms exhibit multiple cell types, it is not the specific stages of the evolutionary transition in individuality (such as group formation or division of labor) that are environmentally induced. Rather, it is the integrated multicellular organism itself that is environmentally induced, complete with division of labor and other properties characteristic of multicellular individuality.

Facultative multicellularity is different from the environmental responses that are the focus of our inquiry in the coming sections. As already mentioned, facultative multicellularity involves an integrated suite of traits that includes all the steps to multicellularity mentioned above. In the coming sections, we break down the evolution of multicellularity into these smaller steps and ask whether plasticity played a role in the evolution of group formation and division of labor. In that way, we aim to focus more on the origins of the steps to multicellularity rather than on their environmental regulation in extant facultatively multicellular species.

We focus on the volvocine green algae, which is a model system for studying the evolution of multicellularity. The volvocine green algae are a monophyletic clade of chlorophycean green algae found in freshwater lakes, streams, and ponds. Extant species range from unicellular to differentiated multicellular and exhibit different degrees of cellular differentiation in the multicellular state, including undifferentiated colonial species, species with sterile somatic cells, and species with 


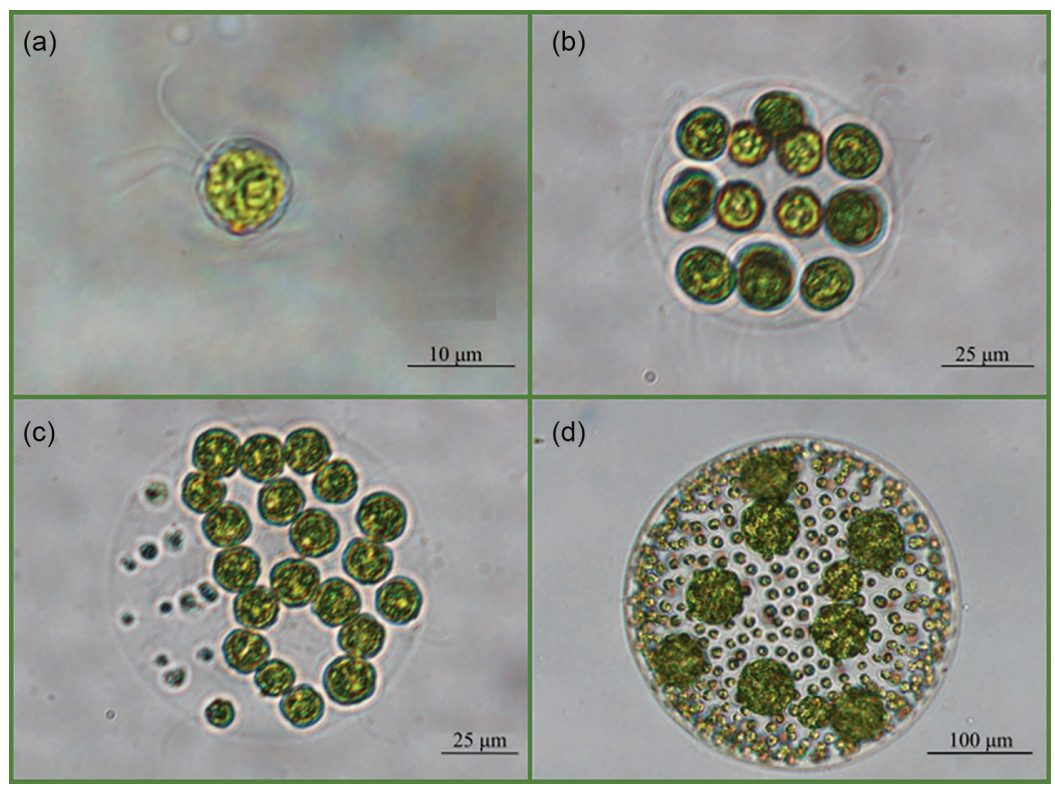

FIGURE 10.1 Four volvocine green algae species that exhibit differences in group formation and cellular differentiation. (a) Unicellular Chlamydomonas reinhardtii strain CC 124. (b) Eudorina elegans strain UTEX 1201, in which member cells are typically undifferentiated, but cooperate in flagellar action and building a structured spherical colony with a colony boundary. (c) Pleodorina starrii strain NIES 1362, which possesses both undifferentiated cells and small somatic cells that do not reproduce and specialize in flagellar action and survival. (d) Volvox carteri strain Eve, which consists of large germ cells specializing in reproduction and small somatic cells specializing in survival.

both specialized germ and specialized somatic cells (Kirk 1999; Michod 2007). Representative species referred to in this chapter are shown in Figure 10.1. Since extant species are hypothesized to have characteristics similar to ancestral species that represented intermediate stages in the evolution of multicellular individuality, the clade is used as a model system to study the evolution of multicellularity (Herron and Michod 2008). The transition to multicellularity in the volvocine green algae occurred approximately 230 mya (Herron et al. 2009), which is relatively recent when compared to transitions in other clades, such as the animals and plants. Some of the genes necessary for somatic cell development in the multicellular volvocine alga Volvox carteri have been identified (Kirk et al. 1999), and the transcriptomic profiles of somatic and germ cells have been characterized (Matt and Umen 2018). The genomes of many of the key species have been sequenced (Merchant et al. 2007; Prochnik et al. 2010; Hanschen et al. 2016; Featherstone et al. 2018; Hamaji et al. 2018). Developmental, physiological, phylogenetic, ecological, molecular, and fitness-based approaches have all been employed in understanding the evolution of multicellularity in this clade (Desnitski 1995; Kirk 1999; Herron et al. 2009; Coleman 2012; Herron 2016). 


\subsection{PLASTICITY AND GROUP FORMATION IN THE VOLVOCINE GREEN ALGAE}

We are using the volvocine green algae to ask whether the initial stage in the evolution of multicellularity, group formation, was an ancestrally plastic response to the environment that later came under developmental-genetic control. Group formation may occur through two routes: (1) via aggregation of cells from different sources, or (2) via daughter cells staying together after cell division, which gives rise to clonal groups of genetically related cells.

In the first route, aggregation typically occurs in response to an environmental cue. The group phenotype only forms following an environmental signal, and at other times the unicellular stage can reproduce in the absence of a group stage. In Chlamydomonas, the close unicellular outgroup to the multicellular volvocine green algae, these environmental cues include changes in nutrient availability and the presence of predators (Iwasa and Murakami 1969; Nakamura et al. 1975; Lurling and Beekman 2006; Khona et al. 2016). Environmental cues such as predation have been hypothesized to selectively favor the evolution of obligate multicellularity (Herron et al. 2019), so the use of this cue for group formation in Chlamydomonas reinhardtii suggests that group formation in this species has previously been acted on by selection.

The second route to multicellularity (clonal group formation) occurs when daughter cells fail to separate after cell division and stay together (Bonner 2000; Fisher et al. 2013; Olson 2013). This can be due to an environmental cue (Tecon and Leveau 2016) or genetic mutation (Ratcliff et al. 2015), and depending on the mechanism, may or may not persist in descendants. Clonal group formation can be either obligate, meaning that it always occurs as part of the life cycle of an organism, regardless of environmental conditions, or facultative, meaning that it only occurs in response to environmental stimuli (Olson 2013). In Chlamydomonas, facultative clonal group formation can occur in response to abiotic and biotic stressors and does not persist in descendants (Mikheeva and Kriuchkova (1980) as cited in Lurling and Beekman (2006); Khona et al. 2016).

Phylogenetic analysis indicates that obligate clonal multicellularity evolved once in the volvocine green algae (Herron and Michod 2008). The ancestor of this clade is inferred to have resembled its close unicellular relative, $C$. reinhardtii, which diverged from its multicellular relatives approximately 255 mya (Herron et al. 2009). Chlamydomonas reinhardtii cells are haploid, flagellated, free-swimming, and photosynthetic. They are phenotypically and genetically similar to the cells comprising the colonial and multicellular species (Merchant et al. 2007; Prochnik et al. 2010; Hanschen et al. 2016; Featherstone et al. 2018; Hamaji et al. 2018).

Chlamydomonas cells form groups called 'palmelloids' in response to environmental stressors, such as predation or nutrient deprivation (Figure 10.2). Palmelloids can be formed by the same two processes by which groups are formed generally: via aggregation or via clonally related cells staying together during development (Olsen et al. 1983; Lurling and Beekman 2006; Khona et al. 2016). Despite these differences, the unifying feature of all palmelloids is that they are cell groups that form in response to environmental cues. 


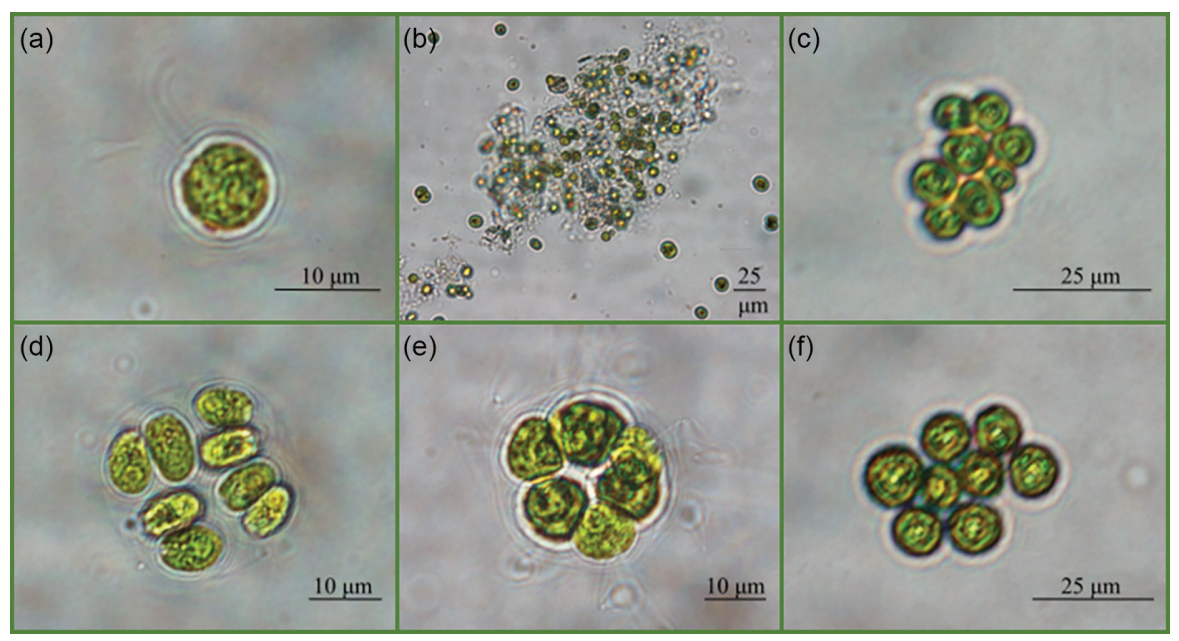

FIGURE 10.2 Unicellular $C$. reinhardtii along with examples of facultative and obligate cell groups discussed in the text. (a) Unicellular C. reinhardtii strain CC 124. (b) A large, disorganized C. reinhardtii CC 124 palmelloid induced by 20 hours of culture in a $150 \mathrm{mM}$ saline solution. (c) A small, more organized C. reinhardtii CC 124 palmelloid induced by 20 hours of culture in a $150 \mathrm{mM}$ saline solution. (d) A C. reinhardtii cell group from population B2-04 experimentally evolved in the presence of a ciliate predator, provided courtesy of M. D. Herron (described in Herron et al. [2019]). (e) The undifferentiated colonial species Pandorina charkowiensis UTEX LB 840. (f) The undifferentiated colonial species Gonium pectorale $\mathrm{K} 4-1$ '十'.

Palmelloids formed by aggregation have been described as disorganized and consist of 10-100,000 cells that can be genetically distinct and can even be comprised of cells from different species (Sathe and Durand 2016). These aggregative palmelloids are held together by the secretion of a gelatinous extracellular matrix. For example, the palmelloid in Figure 10.2b appears to be aggregative. In contrast, palmelloids that develop clonally are made up of smaller, organized clusters of 4-16 cells (Harris 2009). The cells that make up clonal palmelloids are contained within the mother cell wall. The palmelloid in Figure 10.2c appears to be phenotypically consistent with clonal palmelloids, although this needs to be confirmed by developmental studies. This type of palmelloid shares similarities in cell number and spherical cell arrangement with simple colonial volvocine algae species, including Tetrabaena and Pandorina. That said, both types of palmelloids are made up of cells that lose fully functional flagella when in a group, causing the group to lack motility (Lurling and Beekman 2006; Khona et al. 2016), which differentiates them from their obligately colonial relatives. We now discuss the results of several experimental evolution studies which indicate that plastic palmelloid formation may precede the evolution of obligate clonal group formation (Ratcliff et al. 2013; Herron et al. 2019).

Ratcliff et al. (2013) selected $C$. reinhardtii for increased settling rate by propagating algae that settled at the bottom of a centrifuge tube after centrifugation, thereby selecting for large, less motile clusters of cells. The multicellular clusters that evolved 
consisted of up to hundreds of cells, with a mean of 58 per cluster, that reproduced via motile unicells and persisted after the removal of settling selection, indicating the group phenotype came under genetic control. These clusters differed from palmelloids in that they were not transient and instead were stable and heritable. Moreover, the group phenotype was present for most of their life cycle each generation. Also, unlike in aggregative palmelloids, cells within a cluster were clonally related and stayed together after division. The latter characteristic is surprising given that the group phenotype was more similar to aggregative palmelloids than clonal palmelloids. Despite their different developmental program, these multicellular forms shared phenotypic similarities with aggregative palmelloids in that they had similar numbers of cells, were not motile, and were held together by the extracellular matrix.

Herron et al. (2019) experimentally evolved $C$. reinhardtii cell groups in the presence of the unicellular predator Paramecium tetraurelia. The predator could consume the unicells but not the larger cell groups. Group formation was thereby selected for over hundreds of generations. While stable group phenotypes without flagella and with a degree of clonal development evolved in two of the five populations, there was variation in the group morphology and development among isolates from these populations. Cell groups developed in some lines via a mix of aggregation and clonal development; the maternal extracellular matrix kept daughter colonies and unicells together while simultaneously also trapping any unicells that were nearby. The large size, mechanisms underlying group formation, and lack of flagella and clear organization were similar to aggregative palmelloids in these lines. However, such lines differ from palmelloids: group formation has persisted for more than 4 years in the absence of selective reinforcement, and development could be both clonal and aggregative. Other lines evolved obligate cell groups that were phenotypically distinct from the ones held together by extracellular matrix. These lines developed clonally and were held together by the maternal cell wall, and daughter colonies (when released out of the mother colony) typically consisted of 4, 8, or 16 cells. The cells within the group were arranged consistently; this arrangement caused them to morphologically resemble the smaller volvocine green algae and the clonally developing palmelloids.

There are clear phenotypic similarities and key differences among: (1) the clonally developing palmelloids; (2) the clonally developing experimental lines with 4, 8, or 16 cells; and (3) the smaller colonial species with 4, 8, 16, or 32 undifferentiated cells (Herron et al. 2019). In all three cases, development is clonal, cells are enclosed by a cell wall, and cell number is primarily constrained to powers of two. Moreover, predation, the agent of selection in the Herron et al.'s (2019) experimental evolution study, can also induce the development of clonal palmelloids (Lurling and Beekman 2006). Predation is also hypothesized to be a selective pressure that favored the evolution of multicellularity (Stanley 1973; Bonner 1998). However, while colonial volvocine algae species are motile, experimentally evolved Chlamydomonas and Chlamydomonas palmelloids are not (Kirk 1998; Khona et al. 2016; Boyd et al. 2018). Experimentally evolved $C$. reinhardtii cell groups differed from palmelloids in that they remained stable in the absence of predators, whereas palmelloid development occurs in response to environmental cues. It is possible that the experimentally evolved forms began as an adaptive plastic response to the environment and 
were then modified by mutations that spread due to adaptative evolution (Levis and Pfennig 2021). The observations above raise the question of whether group formation in the volvocine green algae evolved via the loss of ancestral plasticity (genetic assimilation (see Scheiner and Levis 2021 in this volume).

In summary, facultative group formation is present in a unicellular outgroup to the multicellular volvocine green algae, with palmelloids sharing phenotypic similarities with experimentally evolved cell groups and simple, obligately multicellular algae species. The observations above raise the question of whether group formation in the volvocine green algae evolved through the loss of ancestral plasticity (genetic assimilation. The plastic phenotype could have come under developmental-genetic control when obligate cell groups evolved in this clade, with secondary modifications affecting traits such as motility.

\subsection{PLASTICITY AND DIVISION OF LABOR IN THE VOLVOCINE GREEN ALGAE}

After cell groups form, cooperation may evolve and along with it, the possibility of defection and the evolution of conflict mediation; that is, developmental mechanisms that enhance cooperation by diminishing the opportunity for, or benefits of, cheating (Michod 2003, 2021). One critical developmental process involving both the evolution of cooperation and the mediation of conflict is reproductive division of labor. Reproductive division of labor occurs when cells specialize in either survival or reproduction, the two basic components of fitness in any organism. The evolution of reproductive division of labor often precedes the evolution of other forms of cellular differentiation (Simpson 2012). The evolutionary priority of reproductive division of labor can be understood in terms of conflict mediation. For other types of somatic cells to evolve, it must first be settled which cells are going to reproduce; otherwise, cells will continually compete for access to the next generation.

During the evolution of multicellularity, reproductive division of labor takes the form of specialized reproductive (germ) and non-reproductive (somatic) cells. Germ and somatic cells are specialized in one of the two basic components of fitness and therefore would have low fitness were they to leave the group and occur in the absence of the other. Consequently, the fitness of groups of specialized cells may be high, even though specialized cells would have low fitness were they alone. As a result, the individuality of the group is enhanced as the fitness at the group level is decoupled from fitness at the cell level (Shelton and Michod 2020). The transfer of fitness to the new level results in a new unit of selection and adaptation-that is, the multicellular individual. After the evolution of germ-soma division of labor, additional cell types can evolve and have evolved in multiple clades. However, in the volvocine green algae additional cell types have not evolved, possibly due to the mechanism of soma determination (i.e., the inhibition of chloroplast development) that prohibits somatic cells from replicating post embryonically (Nedelcu and Michod 2004).

Studies suggest that plasticity has played a role in the evolution of cellular differentiation (Schlichting 2003; Nedelcu and Michod 2006, 2020). Ancestral pathways 
induced by stressful environments in unicellular organisms have been co-opted for use in cellular differentiation during the evolution of multicellularity (Nedelcu and Michod 2006, 2020; Nedelcu 2009). Unicellular organisms, like many organisms, may be expected to downregulate reproduction to survive stressful environments. Such regulation is an example of plasticity that has previously been shaped by adaptive evolution. The same pathways that downregulate reproduction in a unicellular ancestor may be activated in a cell group to produce cells with reduced effort at reproduction; in other words, to produce somatic cells (see discussion of regA in the volvocine algae below). Previously plastic responses to the environment may later become part of normal development and cease being regulated by environmental inputs (Schlichting and Smith 2002; Nedelcu and Michod 2006, 2020; Wagner et al. 2019; see also Levis and Pfennig 2021 in this volume).

The range of cellular differentiation seen in the volvocine green algae make them a useful model system for studying the evolution of cellular differentiation. Multicellular volvocine green algae are typically characterized as having three different categories of cellular differentiation: undifferentiated colonies (where each cell is undifferentiated, and could, in principle, survive and reproduce were it alone), soma-differentiated colonies (with both non-reproductive somatic cells and undifferentiated cells), and germ-soma differentiated colonies (with specialized germ and somatic cells; Kirk 1999). Undifferentiated cells reproduce and have flagella that allow them to swim as well as mix water around the colonies for more efficient nutrient uptake and disposal of waste. Flagella are attached to the cell via basal bodies, which also play an important role in cell division. As a result, flagellar function decreases as cell division proceeds, with flagellar function being lost after about the fifth division (the 32 cell stage) (Koufopanou 1994). Consequently, colonies with 32 or more undifferentiated cells cannot swim and reproduce simultaneously (Koufopanou 1994). However, the evolution of somatic cells with permanent flagella allows large colonies to swim while reproducing (Solari et al. 2006).

Somatic and germ cells have both evolved multiple times within the volvocine green algae (Herron and Michod 2008). Moreover, within one volvocine clade (the Eudorina clade), somatic cells have been gained and/or lost multiple times (Grochau-Wright et al. 2017) (Figure 10.3). When a trait is gained multiple times within a diversifying clade, one possible mechanism underlying such recurrence is that the common ancestor possessed developmental plasticity in the trait of interest (West-Eberhard 2003; Scoville and Pfrender 2010). The recurrent evolution of the trait would then involve plasticity followed by repeated genetic assimilation rather than de novo gains of the trait. Could the repeated evolution of somatic cells shown in Figure 10.3 be explained by the presence of plasticity in the development of somatic cells in the common ancestor of the clade followed by the repeated loss of this plasticity?

To explore this question, we focus on species within the Eudorina clade. The Eudorina clade contains species with all three categories of cellular differentiation: undifferentiated polyphyletic Eudorina species with 8-32 cells, soma-differentiated polyphyletic Pleodorina species with 32-128 cells, and germ-soma differentiated 


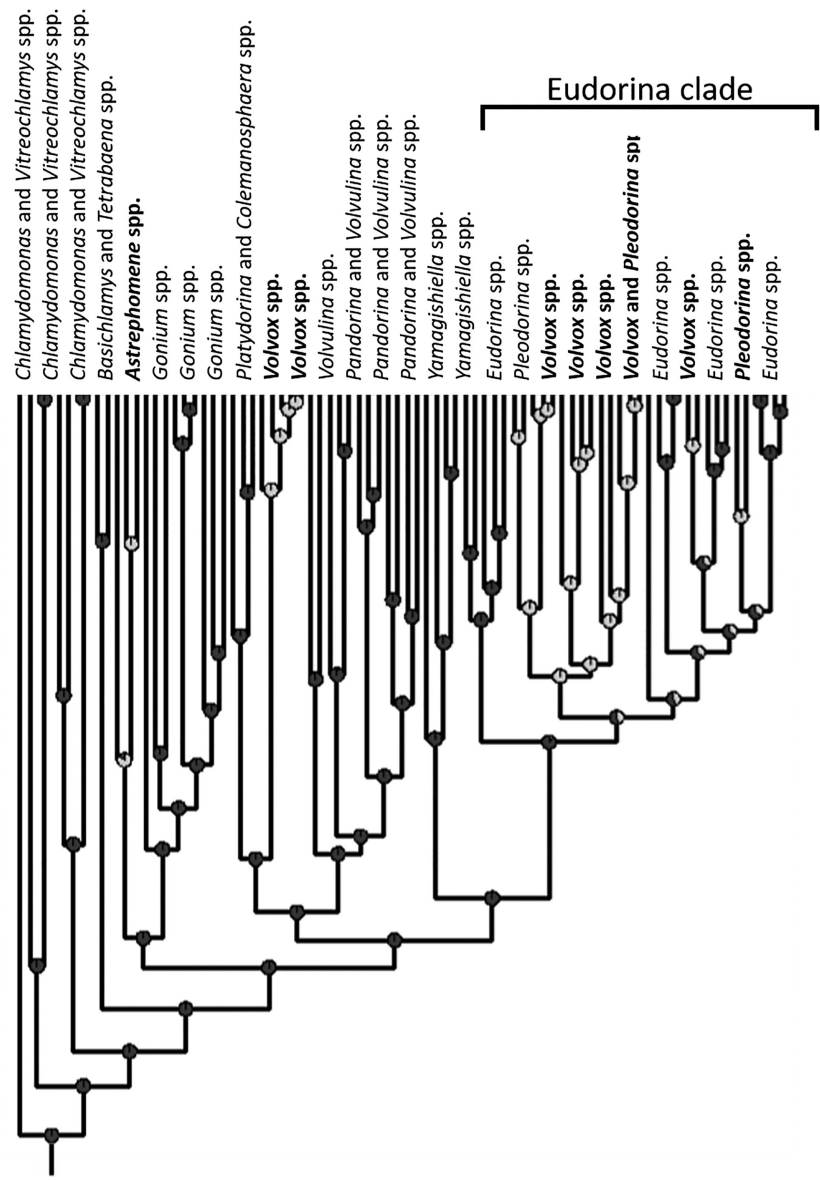

FIGURE 10.3 Volvocine green algae phylogeny illustrating a maximum-likelihood ancestral state reconstruction of obligate somatic cells using an equal rates model. The Eudorina clade, which likely underwent multiple gains and/or losses of obligate somatic cells, is bracketed. Species in bold possess obligate somatic cells and species not in bold are historically characterized as being undifferentiated. Pie charts at nodes indicate support for undifferentiated and soma-differentiated state at that node. Light gray corresponds to support for that node possessing obligate somatic cells and dark gray corresponds to support for that node being undifferentiated. Figure modified from Grochau-Wright et al. (2017).

polyphyletic Volvox species with hundreds to thousands of cells (Figures 10.1 and 10.3). The gene $\operatorname{reg} A$, which is necessary for the development of somatic cells in Volvox carteri, is found in both species with and without somatic cells (GrochauWright et al. 2017). The recurrent gains and/or losses of somatic cells, the diversity of cellular differentiation, and the characterization of part of the underlying genetic pathway make the Eudorina clade an ideal system for examining the potential 
importance of plasticity in the evolution of cellular differentiation and evolutionary transitions in individuality.

Research examining the origin of $\operatorname{reg} A$ indicates that environmental regulation may have played an important role in the evolution of somatic cells. The gene regA encodes a transcription factor and is necessary for somatic differentiation in $V$. carteri (Kirk et al. 1999; Meissner et al. 1999). In regA mutants, cells that otherwise would have remained somatic de-differentiate during development and become capable of reproduction (Kirk 1997).The homolog of regA in the unicellular C. reinhardtii is rlsl. When expressed in $C$. reinhardtii, $r l s l$ causes cells to cease reproduction, similar to the lack of reproduction seen in volvocine algae somatic cells (Nedelcu and Michod 2006; Nedelcu 2009). Although both somatic cells and stressed C. reinhardtii cells lack reproduction, this state is transient and reversible in $C$. reinhardtii, whereas somatic cells in $V$. carteri are terminally differentiated and permanently smaller than reproductive cells. Researchers have hypothesized that the ancestral stress-response of down-regulating reproduction in response to the environment in a unicellular ancestor was co-opted for a new function in a new context: the origination of non-reproductive somatic cells in a multicellular organism (Nedelcu and Michod 2006, 2020; Nedelcu 2009).

The co-option of a life history stress-response gene described above indicates that phenotypic responses to environmental stress may have played a role in the origin of cellular differentiation in the volvocine green algae. In the multicellular context, the previously environmentally regulated response was co-opted to produce the development of somatic cells. While adaptive plasticity played a role in the evolution of somatic cellular differentiation in the volvocine lineage, the intermediate steps are unclear. During the evolution of multicellularity, the origin of undifferentiated cell groups preceded the origin of cellular differentiation. Although we know that the transient down-regulation of reproduction in response to environmental stress was present in unicellular organisms, it remains unclear if somatic-like cells - small, terminally differentiated cells that do not reproducedeveloped in simple colonial organisms in response to stress prior to the evolution of obligate soma.

To determine if somatic-like cells could develop plastically in an undifferentiated species, we recently subjected undifferentiated Eudorina species to an environmental stressor. The genus Eudorina is paraphyletic, but all Eudorina species fall within the Eudorina clade, with some undifferentiated Eudorina species being more closely related to Volvox species than they are to other members of their nominal genus. We focused primarily on E. elegans strain UTEX 1201, which is part of the undifferentiated outgroup to the rest of the Eudorina clade and likely never had a differentiated ancestor (Grochau-Wright et al. 2017). We used 2 hours of cold shock as a stressor, as temperature variation is ecologically relevant for freshwater algae (Similä 1988; Kremer et al. 2018).

We found that cold-shocked colonies developed cells that resembled somatic cells (Figure 10.4); we refer to these cells as somatic-like. Somatic-like cells are living cells with beating flagella that do not reproduce and are smaller than reproductive cells (unpublished data). Somatic-like cells are a plastic response to the environment 


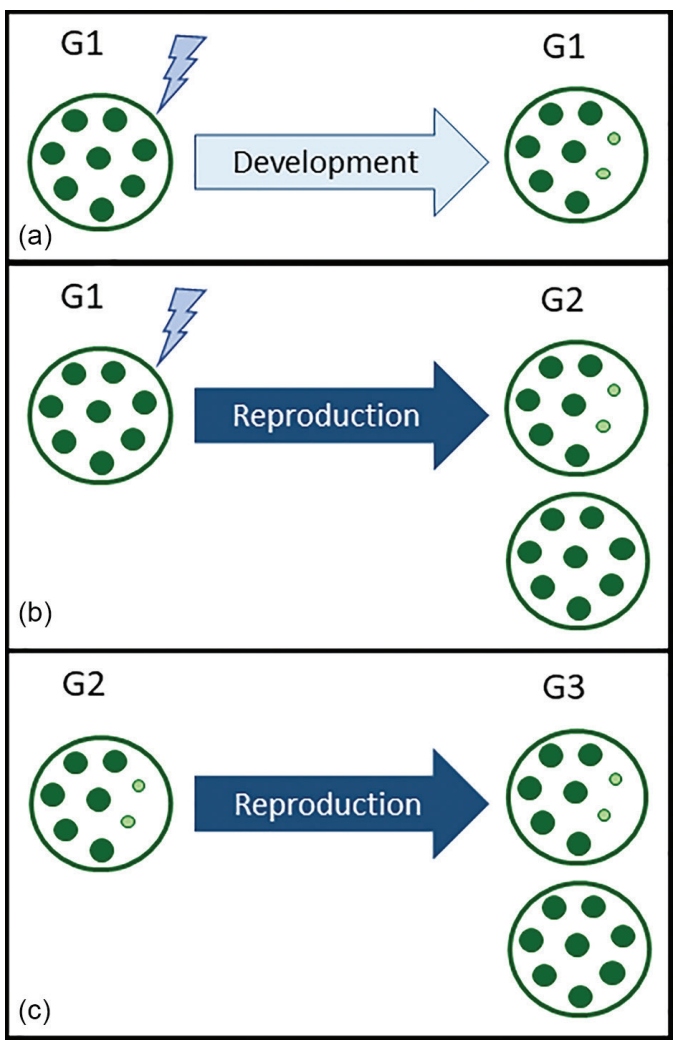

FIGURE 10.4 A schematic representing the production of somatic-like cells in generations 1 (G1), 2 (G2) and 3 (G3). (a) Undifferentiated G1 colonies can develop somatic-like cells after cold shock. (b) Cold-shocked G1 colonies give rise to offspring with and without somatic-like cells. (c) The G3 grand-offspring of cold-shocked G1 colonies can also have daughters with and without somatic-like cells. The proportion of these G3 colonies with somatic-like cells does not differ from that of controls (unpublished data).

and do not persist for more than two generations after cold shock. New cells do not emerge in response to the stressor-instead, previously undifferentiated cells alter their phenotypic state (unpublished data). Full characterization of somatic-like cells is ongoing and will allow us to determine if there are morphological differences between somatic-like cells in generations 1 and 2 .

Somatic-like cells that develop in cold-shocked colonies appear to be a cell-level plastic response to the cold shock. These cells develop within the first generation (G1) when formerly undifferentiated cells alter their phenotypic state in response to the environment. Since cell-level plasticity refers to immediate cell responses to the environment in G1, we hypothesize that cell-level plasticity is present when somaticlike cells are formed in G1.

We also found that cold-shocked colonies produced more daughter colonies with somatic-like cells than do control colonies (Figure 10.4). This indicates that stressed colonies reorganize development to produce somatic-like cells in their offspring 
(transgenerational plasticity; see Bonduriansky 2021). Consequently, we hypothesize that developmental plasticity is present at the level of the colony in G2 colonies. The mechanism underlying cell-level differentiation in direct response to cold shock likely differs from that underlying the development of somatic-like cells in colonies produced by mothers exposed to cold shock. As a result, group-level plasticity is not simply a scaled-up version of cell-level plasticity but is instead a mechanistically distinct property of group development.

Finally, when cold shocking other Eudorina species, we found that phylogenetically distinct Eudorina species developed somatic-like cells following a cold shock. While some of the examined Eudorina species are members of an outgroup to the rest of the Eudorina clade, others fall within the largest part of the clade and are closely related to obligately differentiated species (Figure 10.3). This suggests that the ancestor of the Eudorina clade possessed plastic somatic-like cells that later came under developmental-genetic control.

Taken together, our ongoing work supports the hypothesis that the development of cells that resemble soma are a plastic response to environmental stress and an intermediate step in the evolution of obligate cellular differentiation (Figure 10.5). Interestingly, this plastic response exists at both levels of organization that are central to this evolutionary transition in individuality: the cell and the cell-group or colony level. Cold-shocked cells become somatic-like (cell-level plasticity), and the offspring of cold-shocked colonies develop somatic-like cells (colony-level plasticity). It is unclear whether the occurrence of plastic somatic-like cells is an adaptive response to environmental stress or a by-product of developmental interactions with cold shock. It is also unclear if this response utilizes the same pathway to downregulate reproduction in response to stress as $C$. reinhardtii does. Current work is underway to characterize developmental changes that occur following cold shock and to determine if the expression of regA or related genes is upregulated during the development of somatic-like cells.

\subsection{OTHER EVOLUTIONARY TRANSITIONS IN INDIVIDUALITY}

While this chapter has focused on multicellularity and the volvocine green algae model system, the question remains as to whether plasticity plays a role in other evolutionary transitions in individuality. We conclude by briefly discussing two examples of other evolutionary transitions in individuality in which plasticity is present: the evolution of multicellularity in animals and the evolution of social insect eusociality. Here, we predominantly focus on group formation in choanoflagellates and division of labor in eusocial insects.

\subsubsection{Group Formation in Choanoflagellates and Animals}

Choanoflagellates are the closest relatives of animals and are used as a model system to study the evolution of animal multicellularity (Ruiz-Trillo et al. 2007; King et al. 2008). Choanoflagellates and metazoans likely shared a common ancestor more than 600 mya (King et al. 2008). Multicellular animals have diversified substantially since this time, evolving a range of developmental programs, cell types, tissues, and 


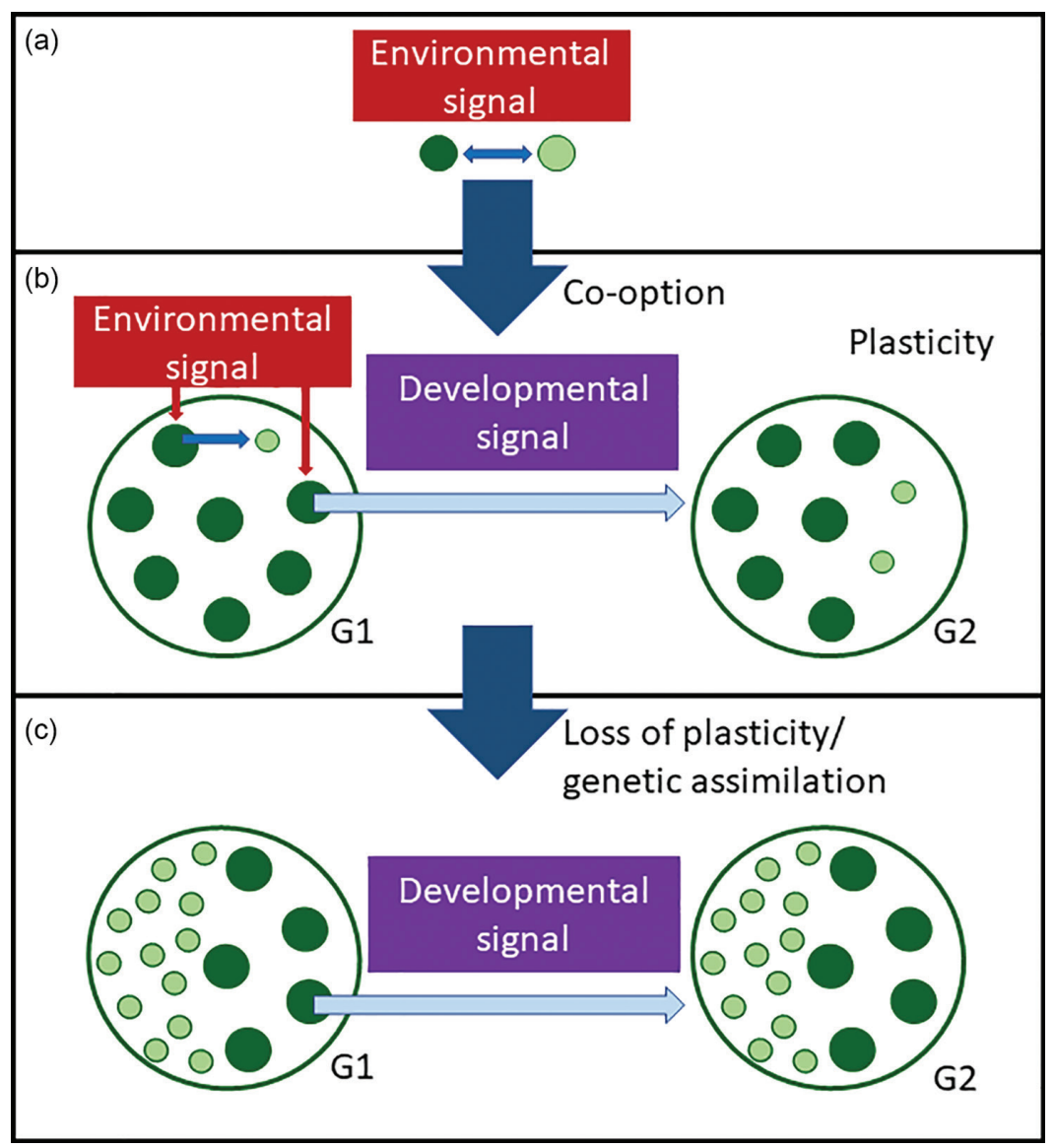

FIGURE 10.5 A schematic illustrating a hypothesized stage in the origin of somatic cells in the volvocine green algae. Nedelcu and Michod (2006) hypothesized that an environmentally regulated gene was co-opted to developmentally produce soma in differentiated species. Figure 10.5 presents a hypothesis for a key intermediate step in this co-option pathway in undifferentiated species. (a) Chlamydomonas reversibly alters its state from reproductive (shown in dark green) to non-reproductive (shown in light green) in response to an environmental signal. (b) The hypothesized intermediate step for the origin of plastic somatic cells in normally undifferentiated species, similar to what is seen in E. elegans (Figure 10.4) and discussed in the text. An environmental signal can cause somatic-like cells (shown as small and light green) to develop from undifferentiated reproductive cells (shown as larger and dark gray) in the generation 1 colony exposed to the stressor, the environmental signal. The red arrow on the left points to a reproductive cell that undergoes cell-level development and becomes a somatic-like cell. The red arrow on the right points to a reproductive cell whose colony-level development is altered. This cell develops into a G2 colony, shown at the right, that can have both reproductive and somatic-like cells. (c) Pleodorina-like colony in which the environmental cue is no longer necessary to induce the development of somatic cells (also shown as small and light green), and that a developmental cue is sufficient. 
morphologies. Morphological similarities between Choanoflagellates and the early branching sponges are apparent and have been used to bolster our understanding of the evolutionary origin of metazoans (Brunet and King 2017).

Choanoflagellates such as Salpinoeca rosetta, Codosiga botrytis, and Desmarella kent exhibit diverse forms of facultative group formation, making multicellular structures in response to environmental conditions, such as an abundance of bacterial prey (Cavalier-Smith 2017). This response allows them to more efficiently capture and consume bacterial prey (Woznica et al. 2016) and involves the integration of multiple traits, indicating that these plastic responses have previously been shaped by adaptive evolution. The multicellular structures are the result of clonal multicellularity: they arise when cells fail to separate after division and remain attached to one another (Fairclough et al. 2010). Two colonial forms (rosettes and chains) can develop in $S$. rosetta.

The earliest multicellular animals may have resembled choanoflagellate rosettes, which are colonial forms in which cells develop in a spherical arrangement, are morphologically distinct from unicells, and are held together by multiple mechanisms (Brunet and King 2017). Several lines of evidence support this. First, the collar complex (a single, apical flagellum surrounded by microvilli) seen in choanoflagellates is present in many animal phyla as part of epidermal, nephridial, or epithelial cells (Salvini 1978; Rieger 2009). This is consistent with animals possessing an ancestral choanoflagellate-like morphology. Second, these collar cells function in nutrient absorption (Takashima et al. 2013), similar to how the collar complex in a rosette sweeps in nutrients. Furthermore, rosettes resemble the blastula (an early developmental stage) in diverse animal phyla. The blastula is a ball of cells that are held together by some of the same mechanisms that hold rosettes together (Dayel et al. 2011, Roberson and Barondes 1983, Lee et al. 1997, SalasVidal and Lomeli 2004).

Studies of choanoflagellate multicellularity suggest that the most recent common ancestor of animals exhibited simple, facultative multicellularity, forming multicellular structures that resembled choanoflagellate rosettes (Nielsen 2008, Arendt et al. 2016). In choanoflagellates, this multicellularity remained inducible by environmental cues. In most animals, multicellularity became obligate and a diverse range of complex morphologies evolved (Brunet and King 2017). Future research should elucidate the novel traits involved in the origin of facultative multicellularity to gain a more complete picture of how multicellularity originated in animals.

\subsubsection{Plasticity in Eusocial Insect Societies}

The evolution of eusocial societies is an evolutionary transition in individuality in which multicellular organisms form highly integrated social groups called eusocial colonies. As in all transitions in individuality, the transition from solitary living to sociality involves the formation of groups and the evolution of cooperation and conflict and conflict mediation, including through division of labor. Division of labor takes the form of castes, in which organisms give up their own reproduction and specialize in facilitating the survival of the group; these organisms are generally 
called workers. Other organisms (typically referred to as queens) specialize in reproduction. Here we focus on the role plasticity plays in the evolution and maintenance of division of labor in eusocial insects.

Eusociality has evolved multiple times in insect clades (Cronin et al. 2013). In Hymenoptera, an insect order containing bees, wasps, and ants, eusociality has evolved at least ten times in the last 100 million years (Bourke 2011). Hymenoptera contains obligately eusocial species with a complete reproductive division of labor between queens and workers. This order also contains solitary species and species with facultative group formation (Hines et al. 2007). A degree of division of labor may have been present as a plastic response in the solitary ancestors of eusocial Hymenoptera. When solitary bees are experimentally placed in a group, they exhibit rudimentary division of labor. Some bees direct their activity towards guarding, while others focus on foraging or colony-building (Wcislo and Danforth 1997; Jeanson et al. 2005). This rudimentary division of labor, expressed in solitary bees in response to changes in their social environment, may have been a preadaptation that set the stage for the evolution of complex division of labor in some lineages (Nowak et al. 2010). In other words, the tendency for behavior to be flexible in different social contexts may have led to the origin of division of labor (Jeanson et al. 2005; Quiñones and Pen 2017).

Studies examining facultatively eusocial species have also shed light on the potential importance of plasticity in the evolution of eusociality. Species such as the facultatively eusocial bee Megalopta genalis will form solitary and social nests in the same population. Solitary nests arise when the female produces all sons in her brood, while social nests arise when at least one daughter stays at the nest as a worker instead of dispersing (Wcislo et al. 2004; Wcislo and Gonzalez 2006; Chambers et al. 2007). Gene expression in the abdomens of facultatively eusocial $M$. genalis is caste-specific, and upregulated genes are rapidly evolving and have likely been targets of selection in obligately eusocial species (Jones et al. 2017). Eusociality may have been ancestrally plastic, with this plasticity later followed by changes in gene regulation and adaptive refinement (plasticity-led evolution; see Levis and Pfennig 2021).

In addition to being important to caste development in species with facultative eusociality, plasticity is also central to caste differentiation in obligately eusocial insects (Nijhout 2003; Corona et al. 2016). In many species, caste determination is triggered primarily by environmental cues, although the relative importance of genes and the environment varies across species (Schwander et al. 2010). Caste development can be affected by nutrition (Smith et al. 2008), temperature, and pheromones (Libbrecht et al. 2013) and is often mediated by the expression of conserved genetic pathways (Berens et al. 2015; Corona et al. 2016). Castes themselves are complex alternative phenotypes and can exhibit distinct morphology, physiology, and behavior. Castes confer benefits to the colony as a whole, as division of labor increases the efficiency of labor and defense, with life history strategies affecting the strength of selection (Fjerdingstad and Crozier 2006).

There are clear parallels between the evolution of eusociality and the evolution of multicellularity. Facultative eusociality is similar to facultative multicellularity in that it is a complex, integrated response to environmental cues. This response 
does not correspond to group formation as is seen in Chlamydomonas palmelloids; instead, it is more similar to facultative multicellularity in Dictyostelium, in which the development of an integrated individual is triggered by environmental cues. Facultative group formation in social insects often includes division of labor, whereas Chlamydomonas palmelloids consist of undifferentiated cells without division of labor. Despite these differences, both evolutionary transitions in individuality are characterized by (1) the presence of plasticity in at least one step, and (2) evidence of ancestral plasticity followed by increasing genetic control of the trait and adaptive refinement.

\subsection{CONCLUSIONS}

This chapter discusses whether phenotypic plasticity played a role in evolutionary transitions in individuality, using the transition from unicellular to multicellular volvocine green algae as a case study. We focused on key steps in the evolution of multicellular individuality - group formation and the evolution of cooperation and conflict through cellular differentiation - and found plasticity to be present throughout those stages. Additional work is needed to determine the extent to which plasticity may have played a role in the origin of novel traits underpinning these steps and to identify the mechanisms involved.

We started by discussing the plastic cell group formation that occurs in response to environmental cues in Chlamydomonas, the unicellular outgroup to the multicellular volvocine green algae, and predicted to be similar to the unicellular ancestor to this clade. We highlighted the phenotypic similarities and differences between Chlamydomonas facultative cell groups called palmelloids, experimentally evolved cell groups, and extant volvocine algae species. The results discussed here provide preliminary support for the hypothesis that group formation was ancestrally plastic in the volvocine green algae before coming under genetic control (genetic assimilation; see Scheiner and Levis [2021]).

We then considered the evolution of cooperation and conflict via division of labor, a key step in the transition from unicellular to multicellular individuality. We presented unpublished, ongoing work finding that undifferentiated species can develop somatic-like cells in response to environmental stress, and hypothesized that plastic cellular differentiation may have been ancestral to a clade in which somatic cells have been gained and/or lost multiple times. This work also reveals that plastic cellular differentiation is likely present at both the level of the cell and the level of the cell group or colony. This is significant for understanding how transitions in individuality proceed because a central component of the evolution of multicellularity is the transition from cell-level traits to group-level traits (Hanschen et al. 2017a). We also reviewed studies showing that Chlamydomonas exhibits temporal changes in reproductive state in response to environmental cues, and that the ancestral gene involved was likely duplicated and co-opted into a gene family necessary for the development of obligate somatic cell differentiation in Volvox (Nedelcu and Michod 2006, 2020; Nedelcu 2009).

While plasticity is present in both group formation and cell differentiation, the extent to which it played a role in the evolution of novel traits underpinning these 
steps remains unclear. During the evolution of group formation in the volvocine green algae, adaptive plasticity could have preceded the fixation and subsequent evolutionary modification of cell groups, similar to what may have occurred in experimental evolution studies (Ratcliff et al. 2013; Herron et al. 2019). More research is needed to determine how the plastic phenotype itself arose. Similarly, the plastic development of somatic cells in response to stress preceded the evolution of obligate somatic cells in the Eudorina clade. This plasticity may have been inherited from stress responses present in a unicellular ancestor and later co-opted for plastic cellular differentiation.

We concluded by briefly discussing the role plasticity may have played in other evolutionary transitions in individuality, focusing on the evolution of animal multicellularity and eusociality in insects. Choanoflagellates, the closest relative of animals, exhibit facultative multicellularity in the presence of bacteria. Plasticity may have also been important in the evolution of eusociality. Some species exhibit facultative group formation with a primitive division of labor; this facultative eusociality is likely ancestral to obligate eusociality. Caste differentiation in obligately eusocial species is also plastic, with caste development utilizing conserved pathways. Additional research is needed to better understand the extent to which plasticity may have facilitated these and other transitions in individuality.

The role of plasticity in evolutionary transitions in individuality remains largely unexplored and may be controversial. As discussed above, researchers have characterized facultative cell group formation in multiple species; however, research examining the evolution of multicellularity has predominately focused on the genetic changes involved in producing multicellular structures (e.g., Ruiz-Trillo et al. 2007; King et al. 2008; Rokas 2008; Cock et al. 2010; Prochnik et al. 2010; Suga et al. 2013; Hanschen et al. 2016). Less attention has been paid to how plasticity may have contributed to the origin of group formation (but see Van Gestel and Tarnita 2017). The role of plasticity in the evolution of cellular differentiation is better understood but is also controversial. While some researchers have argued that plastic responses to the environment may have been instrumental in the origin of new cell types (Schlichting 2003; Gavrilets 2010; Wagner et al. 2019; Nedelcu and Michod 2020), others have emphasized the importance of genetic changes to gene regulatory networks (reviewed in Arendt et al. 2016).

The potential importance of plasticity in two other evolutionary transitions in individuality introduced in Table 10.1 - namely, the origin of the genome and origin of eukaryotes - also requires additional research. Concerning the evolution of eusocial insect societies, researchers have posited that eusociality was ancestrally facultative before coming under genetic control in some lineages (e.g., Jones et al. 2017; Jones and Robinson 2018). Plasticity in caste development has been well-characterized and is uncontroversial (reviewed in Corona et al. 2016).

This chapter lays out the groundwork for examining how plasticity may have contributed to evolutionary transitions in individuality, with a focus on the evolution of multicellularity in the volvocine green algae. Additional research is needed to better understand the role of phenotypic plasticity in evolutionary transitions in individuality (see Box 10.1). 


\section{BOX 10.1 SUGGESTIONS FOR FUTURE}

- Determine if plasticity contributed to the origin of novel traits that underpin evolutionary transitions in individuality ('ETI'). While we discussed evidence that plasticity was present in several key ETI steps, it remains unclear whether plastic responses were responsible for the origin of novel traits that mediate these steps.

- Determine if plasticity was present in other ETI steps. While we focused on group formation and division of labor in this review, there are several other steps in an ETI that we did not discuss here. Plasticity could be present in other traits that mediate ETIs, including those that promote cooperation and mediate conflict.

- Identify the molecular mechanisms underpinning plastic group formation and cellular differentiation in the volvocine green algae. Are the genes and pathways underlying plastic responses the same ones that are responsible for obligate group development and cellular differentiation in closely related species?

- Determine if plastic cellular differentiation at the cell and group levels are examples of adaptive plasticity. Has plastic cellular differentiation been shaped by adaptive evolution or is it is a by-product of interactions between developmental-genetic processes and temperature stress? Additionally, cell-level and group-level plasticity may be underpinned by different pathways and may have different evolutionary implications.

- Use phylogenetic reconstructions to determine when plastic cellular differentiation arose and compare that origin to the origin of key genes necessary for obligate cellular differentiation. Such studies should include reconstructing the evolutionary history of somatic-like cells and will provide insight into evolutionary processes responsible for the evolution of cellular differentiation.

- Examine plasticity in group formation and cellular differentiation in additional ETIs. Work similar to the volvocine algae case study described here should be carried out in other taxa to determine the extent to which the case study can be generalized.

\section{ACKNOWLEDGMENTS}

We thank Aurora Nedelcu, Matthew Herron, De Andre Onyi, Andrew Vizzerra, David Pfennig, and two anonymous reviewers for their helpful comments and suggested changes. We also thank Pierre Durand, Erik Hanschen, and Zach GrochauWright for their feedback on and assistance with the figures and tables. This research was supported by NSF grant DEB-2029999. 


\section{REFERENCES}

Ågren, J. A. 2014. Evolutionary transitions in individuality: Insights from transposable elements. Trends Ecol. Evol. 29:90-96.

Arendt, D., J. M. Musser, C. V. H. Baker, A. Bergman, C. Cepko, D. H. Erwin, M. Pavlicev, G. Schlosser, S. Widder, M. D. Laubichler, and G. P. Wagner. 2016. The origin and evolution of cell types. Nat Rev Genet. 17(12):744-757.

Bellantuono, A. J., K. E. Dougan, C. Granados-Cifuentes, and M. Rodriguez-Lanetty. 2019. Free-living and symbiotic lifestyles of a thermotolerant coral endosymbiont display profoundly distinct transcriptomes under both stable and heat stress conditions. Mol. Ecol. 28:5265-5281.

Bennett, P. M. 2004. Genome plasticity: Insertion sequence elements, transposons and integrons, and DNA rearrangement, pp. 71-113. In N. Woodford and A. P. Johnson, eds., Genomics, Proteomics, and Clinical Bacteriology. Humana Press, Totowa, NJ.

Berens, A. J., J. H. Hunt, and A. L. Toth. 2015. Comparative transcriptomics of convergent evolution: different genes but conserved pathways underlie caste phenotypes across lineages of eusocial insects. Mol. Biol. Evol. 32:690-703.

Bonduriansky, R. 2021. Plasticity across generations. In D. W. Pfennig, ed. Phenotypic Plasticity: Causes, Consequences, and Controversy. CRC Press, Boca Raton, FL.

Bonner, J. T. 2003. On the origin of differentiation. J. Biosci. 28:523-528.

Bonner, J. T. 2000. First Signals: The Evolution of Multicellular Development. Princeton University Press, Princeton, NJ.

Bonner, J. T. 1998. The origins of multicellularity. Integr. Biol. Issues, News, Rev. 1:27-36.

Bourke, A. F. G. 2011. Principles of Social Evolution. Oxford University Press, Oxford, UK.

Boyd, M., F. Rosenzweig, and M. D. Herron. 2018. Analysis of motility in multicellular Chlamydomonas reinhardtii evolved under predation. PLoS One 13:e192184.

Brosius, J. 1999. Genomes were forged by massive bombardments with retroelements and retrosequences. Genetica 107:209-238.

Brunet, T., and N. King. 2017. The origin of animal multicellularity and cell differentiation. Dev. Cell 43:124-140.

Buss, L. W. 1987. The Evolution of Individuality. Princeton University Press, Princeton, NJ.

Cavalier-Smith, T. 2017. Origin of animal multicellularity: Precursors, causes, consequencesthe choanoflagellate/sponge transition, neurogenesis and the Cambrian explosion. Philos. Trans. R. Soc. B Biol. Sci. 372:20150476.

Chambers, I., J. Silva, D. Colby, J. Nichols, B. Nijmeijer, M. Robertson, J. Vrana, K. Jones, L. Grotewold, and A. Smith. 2007. Nanog safeguards pluripotency and mediates germline development. Nature 450:1230-1234.

Cock, J. M., L. Sterck, P. Rouzé, D. Scornet, A. E. Allen, G. Amoutzias, V. Anthouard, F. Artiguenave, J. M. Aury, J. H. Badger, B. Beszteri, K. Billiau, E. Bonnet, J. H. Bothwell, C. Bowler, C. Boyen, C. Brownlee, C. J. Carrano, B. Charrier, G. Y. Cho, S. M. Coelho, J. Collén, E. Corre, C. Da Silva, L. Delage, N. Delaroque, S. M. Dittami, S. Doulbeau, M. Elias, G. Farnham, C. M. M. Gachon, B. Gschloessl, S. Heesch, K. Jabbari, C. Jubin, H. Kawai, K. Kimura, B. Kloareg, F. C. Küpper, D. Lang, A. Le Bail, C. Leblanc, P. Lerouge, M. Lohr, P. J. Lopez, C. Martens, F. Maumus, G. Michel, D. Miranda-Saavedra, J. Morales, H. Moreau, T. Motomura, C. Nagasato, C. A. Napoli, D. R. Nelson, P. Nyvall-Collén, A. F. Peters, C. Pommier, P. Potin, J. Poulain, H. Quesneville, B. Read, S. A. Rensing, A. Ritter, S. Rousvoal, M. Samanta, G. Samson, D. C. Schroeder, B. Ségurens, M. Strittmatter, T. Tonon, J. W. Tregear, K. Valentin, P. Von Dassow, T. Yamagishi, Y. Van De Peer, and P. Wincker. 2010. The Ectocarpus genome and the independent evolution of multicellularity in brown algae. Nature 465:617-621.

Coleman, A. W. 2012. A comparative analysis of the volvocaceae (Chlorophyta). J. Phycol. 48:491-513. 
Corona, M., R. Libbrecht, and D. E. Wheeler. 2016. Molecular mechanisms of phenotypic plasticity in social insects. Curr. Opin. Insect Sci. 13:55-60.

Cronin, A. L., M. Molet, C. Doums, T. Monnin, and C. Peeters. 2013. Recurrent evolution of dependent colony foundation across eusocial insects. Annu. Rev. Entomol. 58:37-55.

Dayel, M. J., R. A. Alegado, S. R. Fairclough, T. C. Levin, S. A. Nichols, K. McDonald, and N. King. 2011. Cell differentiation and morphogenesis in the colony-forming choanoflagellate Salpingoeca rosetta. Dev. Biol. 357:73-82.

Desnitski, A. G. 1995. A review on the evolution of development in Volvox - morphological and physiological aspects. Eur. J. Protistol. 31:241-247.

Durand, P. M., and R. E. Michod. 2010. Genomics in the light of evolutionary transitions. Evolution 64:1533-1540.

Fairclough, S. R., M. J. Dayel, and N. King. 2010. Multicellular development in a choanoflagellate. Curr. Biol. 20:R875-R876.

Featherstone, J., Y. Arakaki, E. R. Hanschen, P. J. Ferris, R. E. Michod, B. J. S. C. Olson, H. Nozaki, and P. M. Durand. 2018. 4-celled Tetrabaena socialis nuclear genome reveals the essential components for genetic control of cell number at the origin of multicellularity in the volvocine lineage. Mol. Biol. Evol. 35:855-870.

Fisher, R. M., C. K. Cornwallis, and S. A. West. 2013. Group formation, relatedness, and the evolution of multicellularity. Curr. Biol. 23:1120-1125.

Fjerdingstad, E. J., and R. H. Crozier. 2006. The evolution of worker caste diversity in social insects. Am. Nat. 167:390-400.

Gavrilets, S. 2010. Rapid transition towards the division of labor via evolution of developmental plasticity. PLoS Comput. Biol. 6:e1000805.

Grochau-Wright, Z. I., E. R. Hanschen, P. J. Ferris, T. Hamaji, H. Nozaki, B. J. S. C. Olson, and R. E. Michod. 2017. Genetic basis for soma is present in undifferentiated volvocine green algae. J. Evol. Biol. 30:1205-1218.

Grosberg, R. K., and R. R. Strathmann. 2007. The evolution of multicellularity: A minor major transition? Annu. Rev. Ecol. Evol. Syst. 38:621-654.

Hamaji, T., H. Kawai-Toyooka, H. Uchimura, M. Suzuki, H. Noguchi, Y. Minakuchi, A. Toyoda, A. Fujiyama, S. Miyagishima, J. G. Umen, and H. Nozaki. 2018. Anisogamy evolved with a reduced sex-determining region in volvocine green algae. Commun. Biol. 1:1-7.

Hanschen, E. R., D. R. Davison, Z. I. Grochau-Wright, and R. E. Michod. 2017a. Evolution of individuality: A case study in the volvocine green algae. Philos. Theory Pract. Biol. 9:1-21.

Hanschen, E. R., D. R. Davison, Z. I. Grochau-Wright, and R. E. Michod. 2017b. Individuality and the major evolutionary transitions, p. 255. In S. Gissis, E. Lamm, and A. Shavit, eds., Landscapes of Collectivity in the Life Sciences. MIT Press, Cambridge, MA.

Hanschen, E. R., T. N. Marriage, P. J. Ferris, T. Hamaji, A. Toyoda, A. Fujiyama, R. Neme, H. Noguchi, Y. Minakuchi, M. Suzuki, H. Kawai-Toyooka, D. R. Smith, H. Sparks, J. Anderson, R. Bakarić, V. Luria, A. Karger, M. W. Kirschner, P. M. Durand, R. E. Michod, H. Nozaki, and B. J. S. C. Olson. 2016. The Gonium pectorale genome demonstrates co-option of cell cycle regulation during the evolution of multicellularity. Nat. Commun. 7:1-10.

Hanschen, E. R., D. E. Shelton, and R. E. Michod. 2015. Evolutionary transitions in individuality and recent models of multicellularity, pp. 165-188. In I. Ruiz-Trillo and A. M. Nedelcu, eds., Evolutionary Transitions to Multicellular Life. Springer, Dordrecht.

Harris, E. H. 2009. The Chlamydomonas Sourcebook (Volume 1). Academic Press, San Diego, CA.

Herron, M. D. 2016. Origins of multicellular complexity: Volvox and the volvocine algae. Mol. Ecol. 25:1213-1223. 
Herron, M. D., J. M. Borin, J. C. Boswell, J. Walker, I. C. K. Chen, C. A. Knox, M. Boyd, F. Rosenzweig, and W. C. Ratcliff. 2019. De novo origins of multicellularity in response to predation. Sci. Rep. 9:1-9.

Herron, M. D., J. D. Hackett, F. O. Aylward, and R. E. Michod. 2009. Triassic origin and early radiation of multicellular volvocine algae. Proc. Natl. Acad. Sci. USA 106:3254-3258.

Herron, M. D., and R. E. Michod. 2008. Evolution of complexity in the volvocine algae: Transitions in individuality through Darwin's eye. Evolution (N. Y) 62:436-451.

Herron, M. D., A. Rashidi, D. E. Shelton, and W. W. Driscoll. 2013. Cellular differentiation and individuality in the "minor" multicellular taxa. Biol. Rev. 88:844-861.

Hines, H. M., J. H. Hunt, T. K. O’Connor, J. J. Gillespie, and S. A. Cameron. 2007. Multigene phylogeny reveals eusociality evolved twice in vespid wasps. Proc. Natl. Acad. Sci. USA 104:3295-3299.

Iwasa, K., and S. Murakami. 1969. Palmelloid formation of Chlamydomonas II. Mechanism of palmelloid formation by organic acids. Physiol. Plant. 22:43-50.

Jeanson, R., P. F. Kukuk, and J. H. Fewell. 2005. Emergence of division of labour in halictine bees: Contributions of social interactions and behavioural variance. Anim. Behav. 70:1183-1193.

Jones, B. M., C. J. Kingwell, W. T. Wcislo, and G. E. Robinson. 2017. Caste-biased gene expression in a facultatively eusocial bee suggests a role for genetic accommodation in the evolution of eusociality. Proc. R. Soc. B Biol. Sci. 284:20162228.

Jones, B. M., and G. E. Robinson. 2018. Genetic accommodation and the role of ancestral plasticity in the evolution of insect eusociality. J. Exp. Biol. 221. doi:10.1242/jeb.153163.

Khona, D. K., S. M. Shirolikar, K. K. Gawde, E. Hom, M. A. Deodhar, and J. S. D’ Souza. 2016. Characterization of salt stress-induced palmelloids in the green alga, Chlamydomonas reinhardtii. Algal Res. 16:434-448.

King, N., M. J. Westbrook, S. L. Young, A. Kuo, M. Abedin, J. Chapman, S. Fairclough, U. Hellsten, Y. Isogai, I. Letunic, M. Marr, D. Pincus, N. Putnam, A. Rokas, K. J. Wright, R. Zuzow, W. Dirks, M. Good, D. Goodstein, D. Lemons, W. Li, J. B. Lyons, A. Morris, S. Nichols, D. J. Richter, A. Salamov, P. Bork, W. A. Lim, G. Manning, W. T. Miller, W. McGinnis, H. Shapiro, R. Tjian, I. V. Grigoriev, and D. Rokhsar. 2008. The genome of the choanoflagellate Monosiga brevicollis and the origin of metazoans. Nature 451:783-788.

Kirk, D. L. 1999. Evolution of multicellularity in the volvocine algae. Curr. Opin. Plant Biol. 2:496-501.

Kirk, D. L. 1998. Volvox: Molecular-Genetic Origins of Multicellularity and Cellular Differentiation. Cambridge University Press, Cambridge.

Kirk, D. L. 1997. The genetic program for germ-soma differentiation in Volvox. Annu. Rev. Genet. 31:359-380.

Kirk, M. M., K. Stark, S. M. Miller, W. Muller, B. E. Taillon, H. Gruber, R. Schmitt, and D. L. Kirk. 1999. regA, a Volvox gene that plays a central role in germ-soma differentiation, encodes a novel regulatory protein. Development 126:639-647.

Koonin, E. V. 2016. Viruses and mobile elements as drivers of evolutionary transitions. Philos. Trans. R. Soc. B Biol. Sci. 371:20150442.

Koufopanou, V. 1994. The evolution of soma in the volvocales. Am. Nat. 143:907-931.

Kremer, C. T., S. B. Fey, A. A. Arellano, and D. A. Vasseur. 2018. Gradual plasticity alters population dynamics in variable environments: Thermal acclimation in the green alga Chlamydomonas reinhartdii. Proc. R. Soc. B Biol. Sci. 285:20171942.

Lamelas, A., M. J. Gosalbes, A. Manzano-Marín, J. Peretó, A. Moya, and A. Latorre. 2011. Serratia symbiotica from the aphid Cinara cedri: A missing link from facultative to obligate Insect Endosymbiont. PLoS Genet. 7:e1002357.

Lee, J. K., P. Buckhaults, C. Wilkes, M. teilhet, M. L. King, K. W. Moremen, and M. Pierce. 1997. Cloning and expression of a Xenophus laevis oocyte lectin and characterization of its mRNA levels during early development. Glycobiology 7:367-372. 
Leitch, A. R., and I. J. Leitch. 2008. Genomic plasticity and the diversity of polyploid plants.

Levis, N. A., and D. W. Pfennig. 2021. Innovation and diversification via plasticity-led evolution. In D. W. Pfennig, ed., Phenotypic Plasticity: Causes, Consequences, and Controversy. CRC Press, Boca Raton, FL.

Levis, N. A.., and D. W. Pfennig. 2016. Evaluating "plasticity-first" evolution in nature: Key criteria and empirical approaches. Trends Ecol. Evol. 31:563-574.

Libbrecht, R., M. Corona, F. Wende, D. O. Azevedo, J. E. Serrão, and L. Keller. 2013. Interplay between insulin signaling, juvenile hormone, and vitellogenin regulates maternal effects on polyphenism in ants. Proc. Natl. Acad. Sci. USA 110:11050-11055.

Lurling, M., and W. Beekman. 2006. Palmelloids formation in Chlamydomonas reinhardtii: Defence against rotifer predators? Int. J. Limnol. 42:65-72.

Matt, G. Y., and J. G. Umen. 2018. Cell-type transcriptomes of the multicellular green alga Volvox carteri yield insights into the evolutionary origins of germ and somatic differentiation programs. G3: Genes, Genomes, Genetics 8:531-550.

Maynard Smith, J., and E. Szathmáry. 1995. The Major Transitions in Evolution. Oxford University Press, Oxford.

Meissner, M., K. Stark, B. Cresnar, D. L. Kirk, and R. Schmitt. 1999. Volvox germlinespecific genes that are putative targets of RegA repression encode chloroplast proteins. Curr. Genet. 36:363-370.

Merchant, S. S., S. E. Prochnik, O. Vallon, E. H. Harris, S. J. Karpowicz, G. B. Witman, A. Terry, A. Salamov, L. K. Fritz-Laylin, L. Maréchal-Drouard, W. F. Marshall, L. H. Qu, D. R. Nelson, A. A. Sanderfoot, M. H. Spalding, V. V. Kapitonov, Q. Ren, P. Ferris, E. Lindquist, H. Shapiro, S. M. Lucas, J. Grimwood, J. Schmutz, I. V. Grigoriev, D. S. Rokhsar, A. R. Grossman, P. Cardol, H. Cerutti, G. Chanfreau, C. L. Chen, V. Cognat, M. T. Croft, R. Dent, S. Dutcher, E. Fernández, H. Fukuzawa, D. González-Ballester, D. González-Halphen, A. Hallmann, M. Hanikenne, M. Hippler, W. Inwood, K. Jabbari, M. Kalanon, R. Kuras, P. A. Lefebvre, S. D. Lemaire, A. V. Lobanov, M. Lohr, A. Manuell, I. Meier, L. Mets, M. Mittag, T. Mittelmeier, J. V. Moroney, J. Moseley, C. Napoli, A. M. Nedelcu, K. Niyogi, S. V. Novoselov, I. T. Paulsen, G. Pazour, S. Purton, J. P. Ral, D. M. Riaño-Pachón, W. Riekhof, L. Rymarquis, M. Schroda, D. Stern, J. Umen, R. Willows, N. Wilson, S. L. Zimmer, J. Allmer, J. Balk, K. Bisova, C. J. Chen, M. Elias, K. Gendler, C. Hauser, M. R. Lamb, H. Ledford, J. C. Long, J. Minagawa, M. D. Page, J. Pan, W. Pootakham, S. Roje, A. Rose, E. Stahlberg, A. M. Terauchi, P. Yang, S. Ball, C. Bowler, C. L. Dieckmann, V. N. Gladyshev, P. Green, R. Jorgensen, S. Mayfield, B. Mueller-Roeber, S. Rajamani, R. T. Sayre, P. Brokstein, I. Dubchak, D. Goodstein, L. Hornick, Y. W. Huang, J. Jhaveri, Y. Luo, D. Martínez, W. C. A. Ngau, B. Otillar, A. Poliakov, A. Porter, L. Szajkowski, G. Werner, and K. Zhou. 2007. The Chlamydomonas genome reveals the evolution of key animal and plant functions. Science 318:245-251.

Michod, R. E. 2021. Multi-level selection of the organism. In M. D. Herron, P. L. Conlin, and W. C. Ratcliff, eds., The Evolution of Multicellularity. CRC Press, Boca Raton, FL.

Michod, R. E. 2007. Evolution of individuality during the transition from unicellular to multicellular life. Proc. Natl. Acad. Sci. 104:8613-8618. National Academy of Sciences.

Michod, R. E. 2003. Cooperation and conflict mediation during the origin of multicellularity. pp. 261-307. In P. Hammerstein, ed., Genetic and Cultural Evolution of Cooperation. MIT Press, Cambridge, MA.

Michod, R. E. 1999. Darwinian Dynamics: Evolutionary Transitions in Fitness and Individuality. Princeton University Press, Princeton, NJ.

Michod, R. E. 1983. Population biology of the first replicators: On the origin of the genotype, phenotype and organism. Am. Zool. 23:5-14.

Michod, R. E., and D. Roze. 2001. Cooperation and conflict in the evolution of multicellularity. Heredity. 86:1-7. 
Mikheeva, T. M., and N. M. Kriuchkova. 1980. Morphological changes of Chlamydomonas sp. and Scenedesmus acuminatus (Lagerh.) Chod. in the presence of zooplankton. Nauchnye Dokl. Vyss. shkoly; Biol. Nauk. 5:60-63.

Nakamura, K., D. F. Bray, and E. B. Wagenaar. 1975. Ultrastructure of Chlamydomonas eugametos palmelloids induced by chloroplatinic acid treatment. J. Bacteriol. 121:338-343.

Nedelcu, A. M. 2009. Environmentally induced responses co-opted for reproductive altruism. Biol. Lett. 5:805-808.

Nedelcu, A. M., and R. E. Michod. 2020. Stress responses co-opted for specialized cell types during the early evolution of multicellularity: The role of stress in the evolution of cell types can be traced back to the early evolution of multicellularity. BioEssays 42:e2000029.

Nedelcu, A. M., and R. E. Michod. 2006. The evolutionary origin of an altruistic gene. Mol. Biol. Evol. 23:1460-1464.

Nedelcu, A. M., and R. E. Michod. 2004. Evolvability, modularity and individuality during the transition to multicellularity in the volvocalean green algae, pp. 466-489. In G. P. Wagner, and G. Schlosser, eds., Modularity in Development and Evolution. Chicago Press, Chicago.

Nielsen, C. 2008. Six major steps in animal evolution: are we derived sponge larvae? Evol. Dev. 10:241-257.

Nijhout, H. F. 2003. Development and evolution of adaptive polyphenisms. Evol. Dev. 5:9-18.

Nowak, M. A., C. E. Tarnita, and E. O. Wilson. 2010. The evolution of eusociality. Nature 466:1057-1062.

Olsen, Y., G. Knutsen, and T. Lien. 1983. Characteristics of phosphorus limitation in Chlamydomonas reinhardtii (Chlorophyceae) at its palmelloids. J. Phycol. 19:313-319.

Olson, B. J. S. C. 2013. Multicellularity: From brief encounters to lifelong unions. eLife 2013.

Prochnik, S. E., J. Umen, A. M. Nedelcu, A. Hallmann, S. M. Miller, I. Nishii, P. Ferris, A. Kuo, T. Mitros, L. K. Fritz-Laylin, U. Hellsten, J. Chapman, O. Simakov, S. A. Rensing, A. Terry, J. Pangilinan, V. Kapitonov, J. Jurka, A. Salamov, H. Shapiro, J. Schmutz, J. Grimwood, E. Lindquist, S. Lucas, I. V. Grigoriev, R. Schmitt, D. Kirk, and D. S. Rokhsar. 2010. Genomic analysis of organismal complexity in the multicellular green alga Volvox carteri. Science 329:223-226.

Quiñones, A. E., and I. Pen. 2017. A unified model of Hymenopteran preadaptations that trigger the evolutionary transition to eusociality. Nat. Commun. 8:1-13.

Ratcliff, W. C., J. D. Fankhauser, D. W. Rogers, D. Greig, and M. Travisano. 2015. Origins of multicellular evolvability in snowflake yeast. Nat. Commun. 6:1-9.

Ratcliff, W. C., M. D. Herron, K. Howell, J. T. Pentz, F. Rosenzweig, and M. Travisano. 2013. Experimental evolution of an alternating uni- and multicellular life cycle in Chlamydomonas reinhardtii. Nat. Commun. 4:1-7.

Resendes De Sousa António, M., and D. Schulze-Makuch. 2012. Toward a new understanding of multicellularity. Hypotheses Life Sci. 2:4-14.

Rieger, R. M. 2009. Monociliated epidermal cells in Gastrotricha: Significance for concepts of early metazoan evolution. J. Zool. Syst. Evol. Res. 14:198-226.

Roberson, M. M., and S. H. Barondes. 1983. Xenophus laevis lectin is localized at several sites in Xenophus oocytes, eggs, and embryos. The J. of Cell Biol. 97:1875-1881.

Rokas, A. 2008. The molecular origins of multicellular transitions. Curr. Opin. Genet. Dev. 18:472-478.

Ruiz-Trillo, I., G. Burger, P. W. H. Holland, N. King, B. F. Lang, A. J. Roger, and M. W. Gray. 2007. The origins of multicellularity: A multi-taxon genome initiative. Trends Genet. 23:113-118.

Salas-Vidal, E., and H. Lomeli. 2004. Imaging filopodia dynamics in the mouse blastocyst. Dev. Biol. 265:75-89. 
Salvini, L. V. 1978. On the origin and evolution of the lower Metazoa. J. Zool. Syst. Evol. Res. 16:40-87.

Sathe, S., and P. M. Durand. 2016. Cellular aggregation in Chlamydomonas (Chlorophyceae) is chimaeric and depends on traits like cell size and motility. Eur. J. Phycol. 51:129-138.

Scheiner, S. M., and N. A. Levis. 2021. The loss of phenotypic plasticity via natural selection: Genetic assimilation. In D. W. Pfennig, ed., Phenotypic Plasticity: Causes, Consequences, and Controversy. CRC Press, Boca Raton, FL.

Schlichting, C. D. 2003. Origins of differentiation via phenotypic plasticity. Evol. Dev. 5:98-105.

Schlichting, C. D., and H. Smith. 2002. Phenotypic plasticity: Linking molecular mechanisms with evolutionary outcomes. Evol. Ecol. 16:189-211. Springer.

Schwander, T., N. Lo, M. Beekman, B. P. Oldroyd, and L. Keller. 2010. Nature versus nurture in social insect caste differentiation. Trends Ecol. Evol. 25:275-282.

Scoville, A. G., and M. E. Pfrender. 2010. Phenotypic plasticity facilitates recurrent rapid adaptation to introduced predators. Proc. Natl. Acad. Sci. USA 107:4260-4263.

Shelton, D. E., and R. E. Michod. 2020. Group and individual selection during evolutionary transitions in individuality: Meanings and partitions. Philos. Trans. R. Soc. B Biol. Sci. 375:20190364.

Similä, A. 1988. Spring development of a Chlamydomonas population in Lake Nimetön, a small humic forest lake in southern Finland, pp. 149-157. In R. Jones, and V. Ilmavirta, eds., Flagellates in Freshwater Ecosystems. Springer, Dordrecht.

Simpson, C. 2012. The evolutionary history of division of labour. Proc. R. Soc. B Biol. Sci. 279:116-121.

Smith, C. R., K. E. Anderson, C. V. Tillberg, J. Gadau, and A. V. Suarez. 2008. Caste determination in a polymorphic social insect: Nutritional, social, and genetic factors. Am. Nat. 172:497-507.

Solari, C. A., J. O. Kessler, and R. E. Michod. 2006. A hydrodynamics approach to the evolution of multicellularity: Flagellar motility and germ-soma differentiation in volvocalean green algae. Am. Nat. 167:537-554.

Stanley, S. M. 1973. An ecological theory for the sudden origin of multicellular life in the late precambrian. Proc. Natl. Acad. Sci. 70:1486-1489.

Suga, H., Z. Chen, A. De Mendoza, A. Sebé-Pedrós, M. W. Brown, E. Kramer, M. Carr, P. Kerner, M. Vervoort, N. Sánchez-Pons, G. Torruella, R. Derelle, G. Manning, B. F. Lang, C. Russ, B. J. Haas, A. J. Roger, C. Nusbaum, and I. Ruiz-Trillo. 2013. The Capsaspora genome reveals a complex unicellular prehistory of animals. Nat. Commun. 4:1-9.

Szathmary, E., and L. Demeter. 1987. Group selection of early replicators and the origin of life. J. Theor. Biol. 128:463-486.

Takashima, S., D. Gold, and V. Hartenstein. 2013. Stem cells and lineages of the intestine: a developmental and evolutionary perspective. Dev. Genes Evol. 223:85-102.

Tecon, R., and J. H. J. Leveau. 2016. Symplasmata are a clonal, conditional, and reversible type of bacterial multicellularity. Sci. Rep. 6:1-10.

Van Gestel, J., and C. E. Tarnita. 2017. On the origin of biological construction, with a focus on multicellularity. Proc. Natl. Acad. Sci. USA 114:11018-11026.

Wagner, G. P., E. M. Erkenbrack, and A. C. Love. 2019. Stress-induced evolutionary innovation: A mechanism for the origin of cell types. BioEssays 41:1800188.

Wcislo, W. T., L. Arneson, K. Roesch, V. Gonzalez, A. Smith, and H. Fernandez. 2004. The evolution of nocturnal behaviour in sweat bees, Megalopta genalis and M. ecuadoria (Hymenoptera: Halictidae): An escape from competitors and enemies? Biol. J. Linn. Soc. 83:377-387.

Wcislo, W. T., and B. N. Danforth. 1997. Secondarily solitary: The evolutionary loss of social behavior. Trends Ecol. Evol. 12:468-474. 
Wcislo, W. T., and V. H. Gonzalez. 2006. Social and ecological contexts of trophallaxis in facultatively social sweat bees, Megalopta genalis and M. ecuadoria (Hymenoptera, Halictidae). Insectes Soc. 53:220-225. Springer.

Wessler, S. R. 1996. Plant retrotransposons: Turned on by stress. Curr. Biol. 6:959-961.

West-Eberhard, M. J. 2003. Developmental Plasticity and Evolution. Oxford University Press, Oxford, UK.

Woznica, A., A. M. Cantley, C. Beemelmanns, E. Freinkman, J. Clardy, and N. King. 2016. Bacterial lipids activate, synergize, and inhibit a developmental switch in choanoflagellates. Proc. Natl. Acad. Sci. USA 113:7894-7899. 